\title{
THE SYSTEM OF COMPUTER MODELING AND INTELLECTUAL MANAGEMENT OF PROGRAMMABLE AGRICULTURAL PRODUCTION BASED ON RETROSPECTIVE DATA
}

\author{
A. F. Rogachev ${ }^{1,2}$, E.V. Melikhova ${ }^{1}$ \\ ${ }^{1}$ Volgograd State Agrarian University, Volgograd \\ ${ }^{2}$ All Russian research Institute of irrigated agriculture, Volgograd
}

Received 12.03.2021

Submitted 25.05.2021

\section{The article was prepared with the financial support of the RFBR and the Administration of the Volgograd region under project No. 19-416-340014}

\begin{abstract}
Summary
The article describes a software system for computer modeling of management of programmable agricultural production based on retrospective data on weather conditions in order to optimize the irrigation regime of agricultural crops for the planned yield.
\end{abstract}

\begin{abstract}
Introduction. Computer support of irrigated land management technologies requires the creation of specialized information and analytical systems. The article discusses the creation of information and analytical systems for collecting, storing and analyzing numerous data on the components of natural impact on grown plants and the results of long-term exploitation of irrigated agricultural land [1]. Materials and methods. The aim of the study is to substantiate the architecture and develop a program for managing programmed agriculture, in particular, the water regime of irrigated crops with various methods of irrigation in the modes of project and operational management. Substantiated is the simulation of mathematical modeling of the development and water consumption of plants, taking into account the type and method of irrigation of the crop, agro-climatic conditions of cultivation, including agrotechnological characteristics of the soil, as well as the phases of vegetation, taken into account with the sum of accumulated temperatures. The Penman-Monteith dependence was taken as the algorithmic kernel for calculating the model to determine the value of the reference evapotranspiration. The calculation of the simulated current value of soil moisture in the predicted mode was carried out according to the Alpatiev formula. For the synthesis of information systems, well-known methods of their design were used, including the synthesis of the database structure and the implementation of the above algorithms. Results and conclusions. The created information systems of the reference category are designed to provide a set of auxiliary information about the parameters of a controlled object or process, while the assessment of information is entrusted to the decision-maker. The basic components of the system have been developed, including the computer program «Optimization of the technology of irrigation of agricultural crops for the planned yield», the database «Parameters for calculating irrigation regimes for agricultural crops, taking into account the heat and moisture supply of the region» of the relational type, connecting their interfaces, as well as the technology of use. The program implements a visual visualization of the results of the calculations performed, in particular, the dynamics of the moisture content in the soil, which, if necessary, can be output to a file and print. The composition of the indicators displayed by the program can be flexibly customized according to the user's requirements. The use of computerized information and advisory systems in irrigated agriculture makes it possible to increase the scientific validity in the implementation of the specified irrigation regimes for agricultural crops. The developed software system, functioning in two modes - predictive and corrective, provides an increase in the sustainability of agricultural crops cultivation, achieved by increasing the validity of the management of irrigation processes based on predicting the timing and number of irrigations calculated for a given yield. The use of information and advisory systems, implemented through the developed computer program, for the cultivation of irrigated crops, ensures the economy of irrigation water and increases the validity of management decisions in the field of growing irrigated crops by ensuring the possibility of more accurate compliance with the projected parameters of the irrigation regime.
\end{abstract}


Keywords: programmable agricultural production. computer modeling, control system, retrospective data, yield.

Citation. Rogachev A. F., Melikhova E.V. The system of computer modeling and intellectual management of programmable agricultural production based on retrospective data. Proc. of the Lower Volga Agro-University Comp. 2021. 2(62). 390-403 (in Russian). DOI: 10.32786/2071-9485-2021-02-40.

Author's contribution. All authors of this research paper have directly participated in the planning, execution, or analysis of this study. All authors of this paper have read and approved the final version submitted.

Conflict of interest. The authors declare no conflict of interest.

УДК 631.4:519.85

СИСТЕМА КОМПЬЮТЕРНОГО МОДЕЛИРОВАНИЯ

И ИНТЕЛЛЕКТУАЛЬНОГО УПРАВЛЕНИЯ ПРОГРАММИРУЕМЫМ АГРАРНЫМ ПРОИЗВОДСТВОМ НА ОСНОВЕ РЕТРОСПЕКТИВНЫХ ДАННЫХ

\author{
А. Ф. Рогачев ${ }^{\mathbf{1 , 2}}$, доктор технических наук, профессор \\ Е. В. Мелихова ${ }^{1}$, доктор технических наук, дочент \\ ${ }^{1}$ Волгоградский государственный аграрный университет, г. Волгоград \\ ${ }^{2}$ Всероссийский научно-исследовательский институт орошаемого земледелия, г. Волгоград
}

Дата поступления в редакцию 12.03.2021

Дата принятия к печати 25.05.2021

\title{
Статья подготовлена при финансовой поддержске РФФИ и Администрации Волгоградской области по проекту № 19-416-340014
}

Актуальность. Компьютерное обеспечение технологий управления орошаемыми землями требует создания специализированных информационно-аналитических систем (ИАС). В статье рассматривается создание ИАС, предназначенных для сбора, хранения и анализа многочисленных данных о компонентах природного воздействия на выращиваемые растения и результатах многолетней эксплуатации орошаемых земель сельскохозяйственного назначения. Материалы и методы. Целью исследования являются обоснование архитектуры и разработка программы управления программируемым земледелием, в частности водным режимом орошаемых сельскохозяйственных культур при различных способах орошения в режимах проектного и оперативного управления. Обосновано проведение имитационного математического моделирования развития и водопотребления растений, учитывающего вид и способ полива культуры, агроклиматические условия возделывания, включая агротехнологические характеристики почвы, а также фазы вегетации, учитываемые с суммой накопленных температур. Алгоритмическим ядром расчета модели принималась зависимость Пенмана-Монтейта для определения значения эталонной эвапотранспирации. Расчет моделируемого текущего значения влажности почвы в прогнозном режиме производился по формуле Алпатьева. Для синтеза информационных систем (ИС) использовались известные методы их проектирования, включая синтез структуры базы данных (БД) и реализацию приведенных алгоритмов. Результаты и обсуждение. Создаваемые ИС категории справочные предназначены для обеспечения совокупностью вспомогательной информацией о параметрах управляемого объекта либо процесса, при этом оценивание информации возложено на лицо, принимающее решение ЛПР. Разработаны базовые компоненты системы, включая компьютерную программу «Оптимизация технологии орошения сельскохозяйственных культур под планируемую урожайность», базу данных «Параметры для расчета режимов орошения сельскохозяйственных культур с учетом тепло- и влагообеспеченности региона» реляционного типа, связывающие их интерфейсы, а также технологию использования. Программой реализована наглядная визуализация результатов выполняемых расчетов, в частности динамики содержания влаги в почве, которая при необходимости может выводиться в файл и на печать. Состав выводимых программой показателей можно гибко настраивать по требованиям пользователя. Выводы. Применение компьютеризованных информационносоветующих систем (ИСС) в орошаемом земледелии позволяет повысить научную обоснован- 
ность при реализации задаваемых режимов орошения сельскохозяйственных культур. Разработанная программная система, функционирующая в двух режимах - прогнозном и корректирующем, обеспечивает повышение устойчивости возделывания сельскохозяйственных культур, достигаемое за счет повышения обоснованности управления оросительными процессами на основе прогнозирования сроков и числа поливов, рассчитываемых под заданную урожайность. Применение ИСС, реализуемых посредством разработанной компьютерной программы, для выращивания орошаемых сельскохозяйственных культур, обеспечивает экономию оросительной воды и повышение обоснованности управленческих решений в области выращивания орошаемых сельскохозяйственных культур за счет обеспечения возможности более точного выдерживания запроектированных параметров режима орошения.

Ключевые слова: программируемое сельскохозяйственное производство, компьютерное моделирование, ретроспективные данные, ИСС.

Цитирование. Рогачев А. Ф., Мелихова Е. В. Система компьютерного моделирования и интеллектуального управления программируемым аграрным производством на основе ретроспективных данных. Известия НВ АУК. 2021. 2(62). 390-403. DOI: 10.32786/2071-9485-2021-02-40.

Авторский вклад. Все авторы настоящего исследования принимали непосредственное участие в планировании, выполнении или анализе данного исследования. Все авторы настоящей статьи ознакомились и одобрили представленный окончательный вариант.

Конфликт интересов. Авторы заявляют об отсутствии конфликта интересов.

Введение. Обеспечение стабильного эколого-мелиоративного состояния агроландшафтов, предотвращение их водной деградации и выхода из строя возможно за счет повышения качества управления в области использования орошаемых земель, которое требует компьютерной поддержки на основе цифровых информационных технологий (ИТ). Компьютерное обеспечение технологий управления орошаемыми землями требует создания специализированных информационно-аналитических систем [1], предназначенных для сбора, хранения и анализа многочисленных данных о компонентах природного воздействия на выращиваемые растения и результатах многолетней эксплуатации орошаемых земель сельскохозяйственного назначения [1].

Повышение качества управления эксплуатацией гидромелиоративных систем и его научной обоснованности, предотвращение деградации и выбытия орошаемых земель требует совершенствования компьютерных информационных систем. Такие системы предназначены для выборки экономически обоснованных управленческих решений по оптимизации возделывания сельскохозяйственных культур на основе анализа многочисленных данных и информации о природных условиях и техногенных показателях состояния мелиоративных земель. Для рационализации использования ограниченных водных ресурсов требуется применение компьютерной системы по поддержке управленческих решений по распределению подачи воды на севообороты, функционирующей на базе оптимизационных математических алгоритмов, включая нейросетевые [5, 16].

Исследованию цифровых ИТ и математических алгоритмов в управлении гидромелиоративными процессами посвящены работы Кружилина И. П., Щедрина В. Н., Бородычева В. В., Васильева С. М., Гагарина А. Г., Лытова М. Ю., Иванова П. В., Кавокина А. А., Кардаша В. А., Корсака В. В., Николаенко А. Н., Пронько Н. А., Фальковича А. С., Юрченко И. Ф. и др. [10, 11, 12].

Компьютеризованные технологии управления мелиоративной деятельностью, включая системы поддержки решения (СПР), по функциональному назначению делятся на информационно-справочные, советующие и управляющие. 
Совокупность агробиологических и технологических параметров состояния орошаемых земель и природно-климатических факторов, в условиях техникотехнологических, эколого-экономических ограничений, определяют потребность в создании оптимизированных систем поддержки решения при возделывании орошаемых культур [7, 9]. Последние могут использовать данные дистанционного зондирования почв, получаемые с помощью спутников и БПЛА, мобильных технологических агрегатов и ДМ, а также посредством ГИС-технологий $[1,4,13,18]$.

Материалы и методы. Целью исследования является обоснование архитектуры и разработка программы управления водным режимом орошаемых сельскохозяйственных культур при различных способах орошения в режимах проектного и оперативного управления.

С целью управления водным режимом возделываемых культур необходимо проведение математического, в том числе имитационного, моделирования процессов их развития и водопотребления $[5,14,15,17]$. Моделирование позволяет учитывать вид и способ полива культуры, агроклиматические условия возделывания, включая агротехнологические характеристики почвы, а также фазы вегетации, учитываемые с суммой накопленных температур и др. [12].

Алгоритмическим ядром расчета модели может приниматься зависимость (1) Пенмана-Монтейта для определения значения эталонной эвапотранспирации $E T_{0}$, [9], определяющая суммарное подекадное водопотребление и описываемое формулой:

$$
E T_{0}=\frac{0.408 \Delta\left(R_{n}-G\right)+\gamma \frac{900}{t+273} U_{2}\left(e_{s}-e_{a}\right)}{\Delta+\gamma\left(1+0.34 U_{2}\right)},
$$

где $R_{n}$ - уровень чистой радиации на поверхности растений, $G$ - плотность воздействующего на почву теплового потока, $t$ - температура воздуха, среднесуточно определяемая на высоте $2 \mathrm{M}$, $U_{2}$ - скорость ветра на этой же высоте, $e_{s}$ - давление насыщения водяного пара, $e_{a}-$ фактическое давление водяного пара, $\Delta$ - уклон кривой давления водяного пара, $\gamma$ - значение психрометрической константы.

Расчет моделируемого текущего значения $W$ влажности почвы в прогнозном режиме производился по математической зависимости (2):

$$
W=W-K t * K t_{\text {попр }} * S t_{j} * K o f+\frac{P_{j}}{D},
$$

где $K t$ - переменное значение биоклиматического коэффициента, вычисляемое для текущей суммы накопленных среднесуточных температур; $K t_{\text {nопр }}$ - корректирующий коэффициент для $K t ; S t t_{j}$ - среднедекадная температура для декады $j ;$; $o f$ - коэффициент влагообмена, определяемый для текущего значения накопленной суммы температур; $P_{j}$ - суммарные осадки для декады $j ; D$ - количество дней в текущей декаде.

Для синтеза ИС использовались известные методы их проектирования, включая синтез структуры базы данных (БД) и реализацию приведенных алгоритмов $[2,3,7,8]$.

Код разработанной программы ИС реализовывался в среде Borland Delphi 7, формат данных принимался dBase 4. Программа предназначена для решения следующих основных задач:

- $\quad$ ведение БД параметров оросительных технологий;

- $\quad$ интерактивная поддержка реализации научно обоснованных режимов орошения;

- $\quad$ визуализация и экспорт результатов расчетов

База статистических данных технологий орошения и параметров севооборотов включает более десятка нормализованных реляционных таблиц, взаимосвязанных между собой. 
Результаты и обсуждение. Создаваемые информационные системы (ИС) категории справочные предназначены для обеспечения совокупностью вспомогательной информации о параметрах управляемого объекта либо процесса, при этом оценивание информации возложено на лицо, принимающее решение ЛПР. Информационносоветующие системы (ИСС) обеспечивают более высокий уровень автоматизации, дополнительно генерируя некоторые альтернативы управленческих решений, которые могут приниматься и анализироваться ЛПР [3]. В отличие от них информационноуправляющие системы (ИУС) реализуют высшую степень автоматизации, реализуя вырабатываемые автоматически управленческие решения [9].

Согласно этой классификации, разработанная в Лаборатории прогнозирования урожайности сельскохозяйственных культур Волгоградского ГАУ совместно с ВНИИОЗ компьютерная программа «Оптимизация и оперативное управление технологиями орошения сельскохозяйственных культур под планируемую урожайность» (свидетельство о государственной регистрации № 2008613351) относится к ИСС. Интерактивный интерфейс разработанной программы позволяет организовать взаимодействие с БД (Свидетельство о государственной регистрации № 2017620719).

Алгоритмическое ядро программы включает 5 блоков: метеоданные; параметры почв; совокупность биологических данных; технико-технологические данные; блок моделирования и расчетов. Для наглядности и удобства выбора вкладки на главном окне программы выделены разными цветами. Вкладки задают алгоритм последовательного ввода исходных данных, реализуемый перед использованием программы.

Первая вкладка «Метеорологический блок» обеспечивает интерактивный ввод гидрометеоданных, получаемых по метеостанциям федеральных округов: полные даты; температуры воздуха; атмосферные осадки; скорость ветра; влажность воздуха (рисунок 1). Отдельная кнопка «Календарь» вызывает окно календаря, облегчая подекадное заполнение Метеоданных.

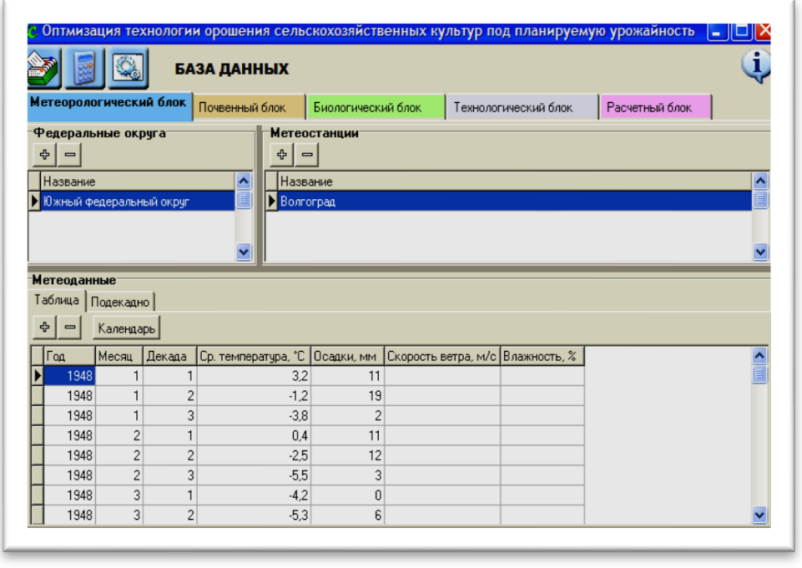

a)

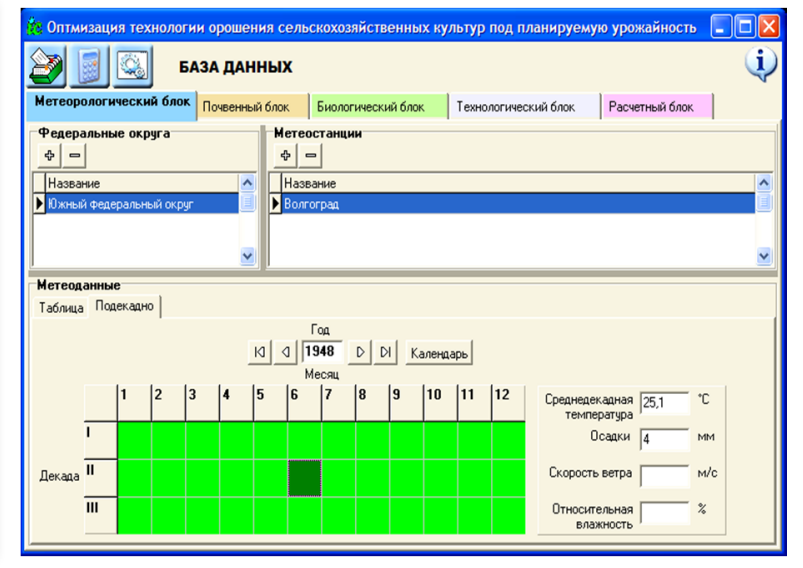

б)

Рисунок 1 - Рабочие окна разработанной программы: Метеорологический блок БД; a) табличное представление метеоданных; б) подекадное представление метеоданных)

Figure 1 - Working windows of the developed program: Meteorological database block; a) tabular representation of meteorological data; b) sub-decadal representation of meteorological data)

Вторая из вкладок интерфейса программы «Почвенный блок» (рисунок 2) объединяет поля ввода данных об орошаемых почвах. К ним относятся все основные характеристики почвы. Для отдельных способов орошения предусмотрены дополнительные данные, например, при поливе по бороздам или полосам вводится удельный расход воды. 


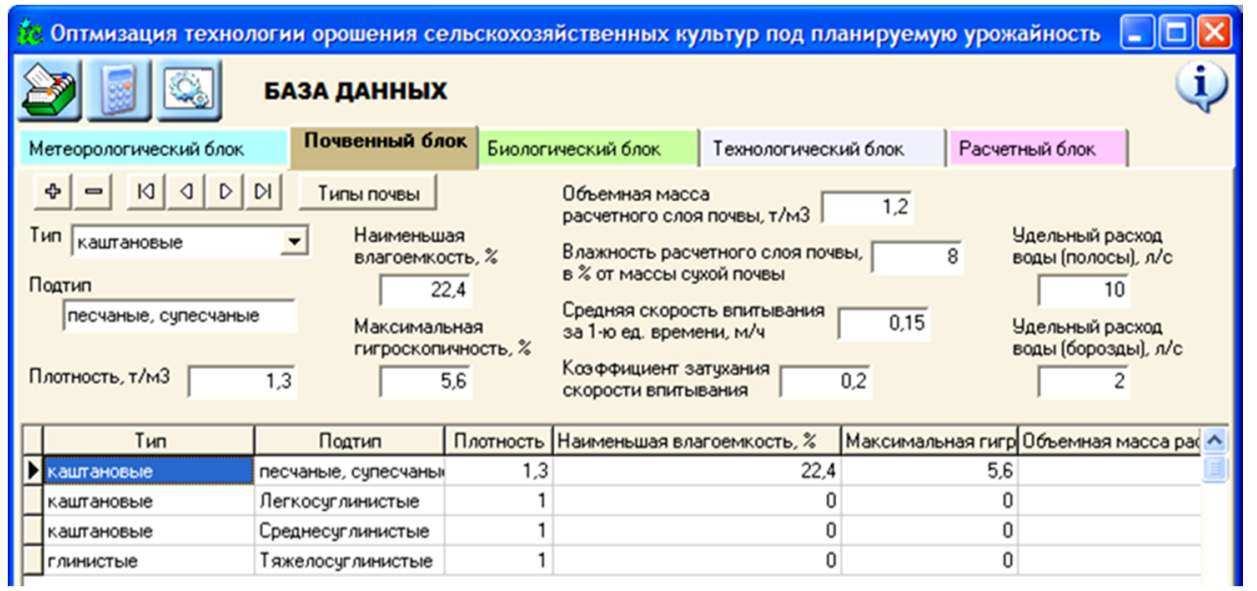

Рисунок 2 - Окно вкладки «Почвенный блок» интерфейса ввода данных

Figure 2 - Window of the "Soil block" tab of the data entry interface

Совокупность сведений о сельскохозяйственных культурах вводят в рабочем окне третьей вкладки - «Биологический блок». Вкладка «Биологический блок» интерфейса программы (рисунок 3) объединяет поля ввода данных о сельскохозяйственных культурах.

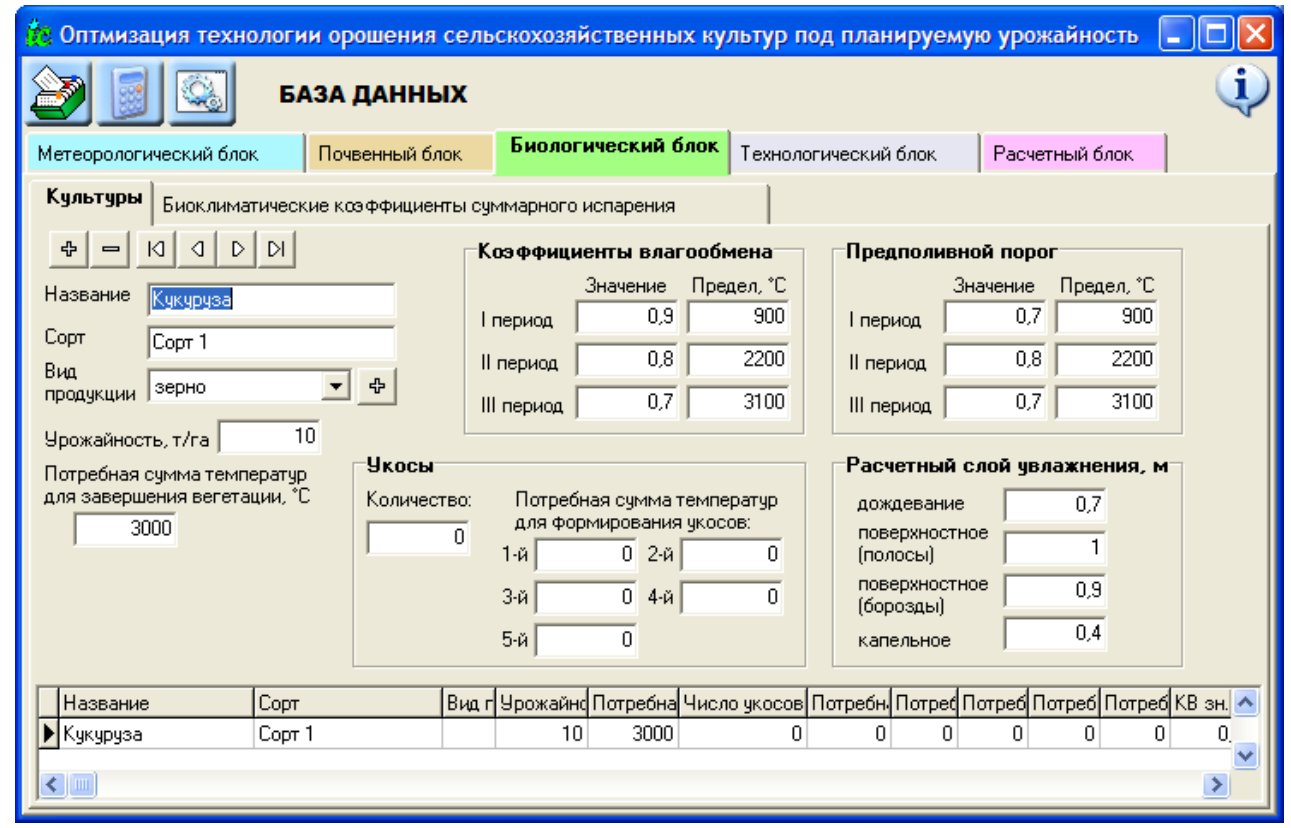

Рисунок 3 - Рабочее окно «Биологический блок»

Figure 3 - Working window «Biological block»

Данные о культурах включают наименование и сорт возделываемой сельскохозяйственной культуры, а также вид получаемой продукции. Также вводятся урожайность; сумма накопленных температур для установления момента завершения вегетации и ряд других. Кнопка «Виды продукции» позволяет вызвать окно Справочника видов продукции (рисунок 4).

Дополнительная вкладка «Биоклиматические коэффициенты» обеспечивает ввод значений величин биоклиматических коэффициентов испарения по каждой из культур с учетом накопленной суммы температур. 


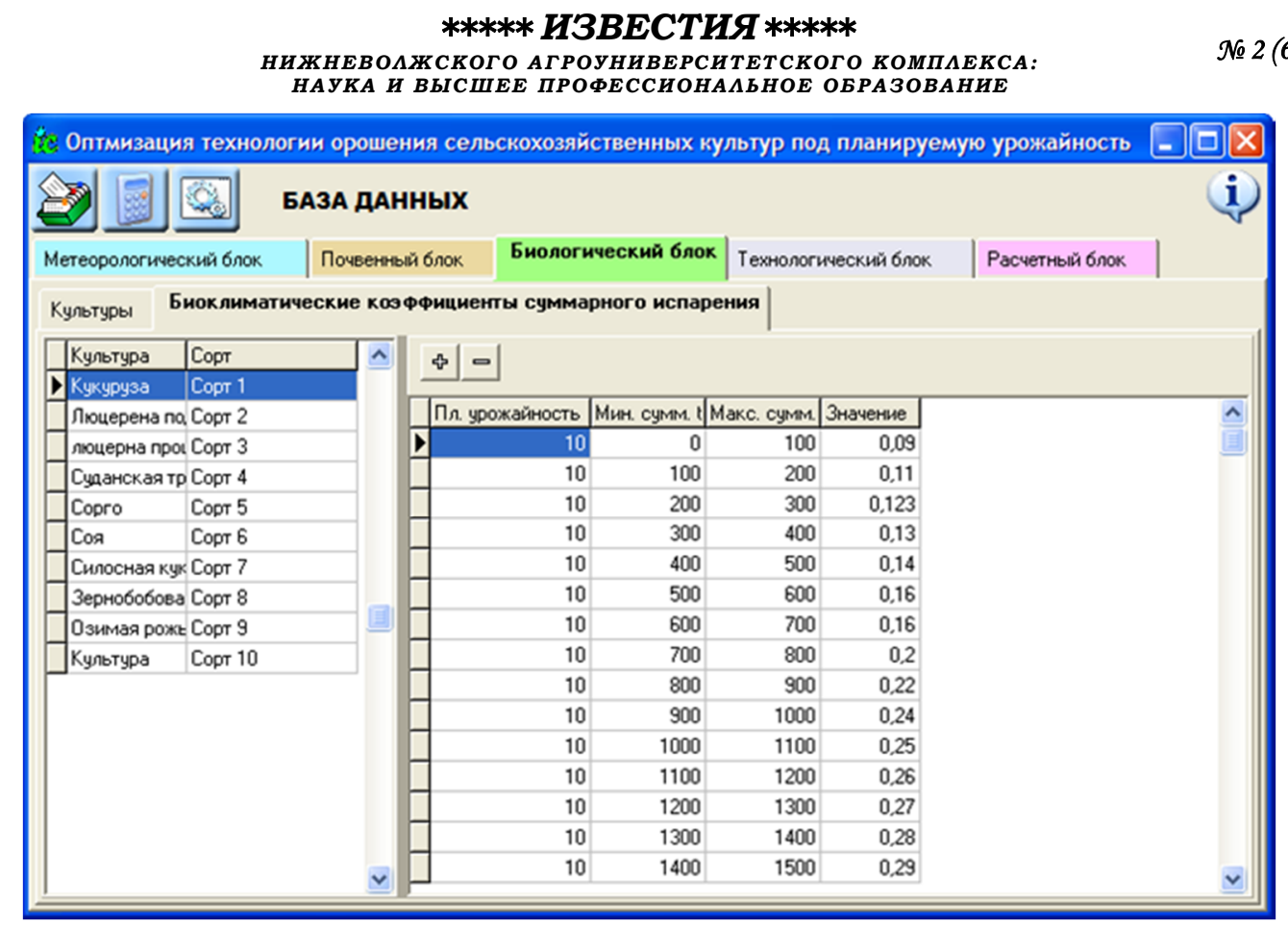

Рисунок 4 - Справочник «Виды сельскохозяйственной продукции», режим «Ввод биоклиматических коэффициентов суммарного испарения»

Figure 4 - Reference book «Types of agricultural products», mode «Input of bioclimatic coefficients of total evaporation»

Процедура интерактивного ввода данных в форму вкладки частично автоматизирована. Значение планируемой урожайности дублируется из предыдущей строки; значение минимальной суммы температур приравнивается к значению максимальной суммы температур из предыдущей строки; значение максимальной суммы температур увеличивается на разность температур в предыдущей строке; значение биоклиматического коэффициента дублируется из предыдущей строки.

На четвертой вкладке «Технологический блок» сведены данные о поливальных машинах [10]; значения расхода воды, а также коэффициенты, характеризующие использование дождевальными машинами (ДМ) рабочего времени (рисунок 5).

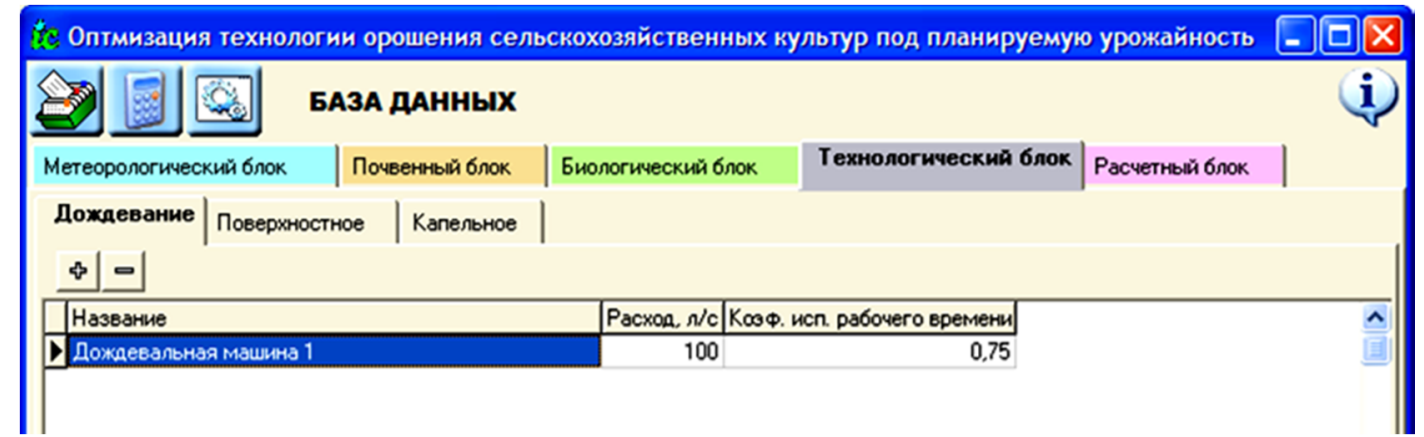

Рисунок 5 - Интерфейс вкладки «Технологический блок»: ввод типа и параметров ДМ

Figure 5 - Interface of the «Process unit» tab: entering the type and parameters of the sprinkler machine

На пятой вкладке «Расчетный блок» предусмотрен ввод параметров для расчета влажности - данные о значениях коэффициента испарения и $\mathrm{m}_{\mathrm{e}}$ (рисунок 6) для различных скоростей ветра и температурах воздуха для различных периодов вегетации. 


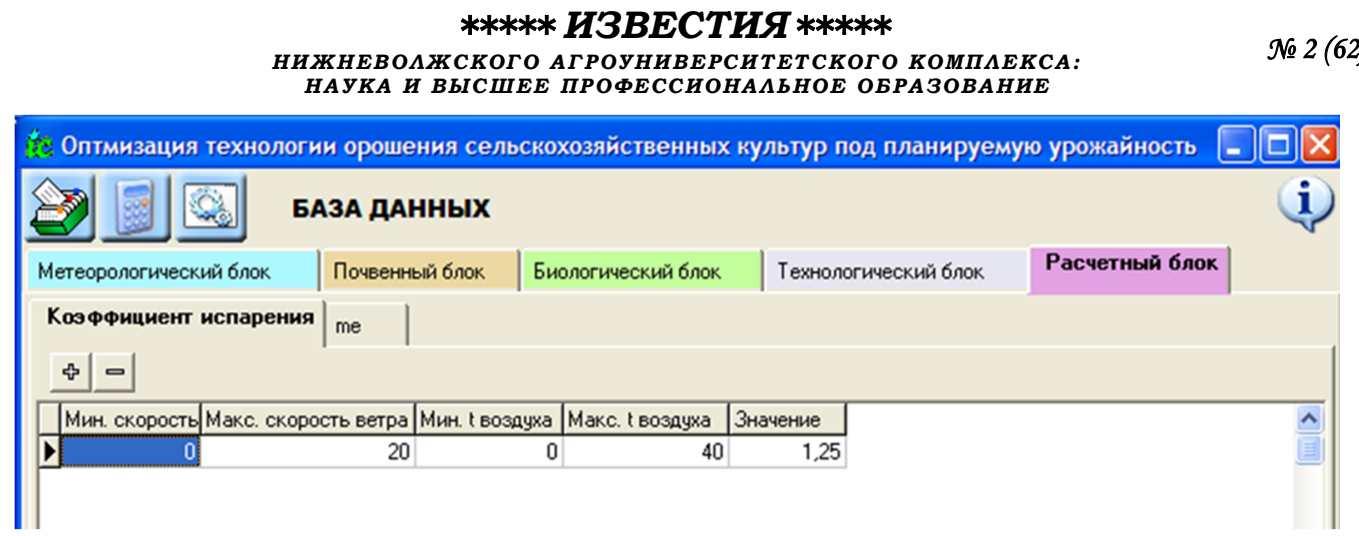

Рисунок 6 - Интерфейс вкладки «Расчетный блок»: ввод коэффициента испарения

Figure 6 - Interface of the Calculation Block tab: entering the evaporation coefficient

Разработанная Программа может использоваться в двух основных режимах:

- прогнозном:

- корректирующем.

Прогнозный режим обеспечивает расчет под планируемую урожайность значений поливных норм, числа и продолжительностей поливов, оросительных норму (рисунок 7).

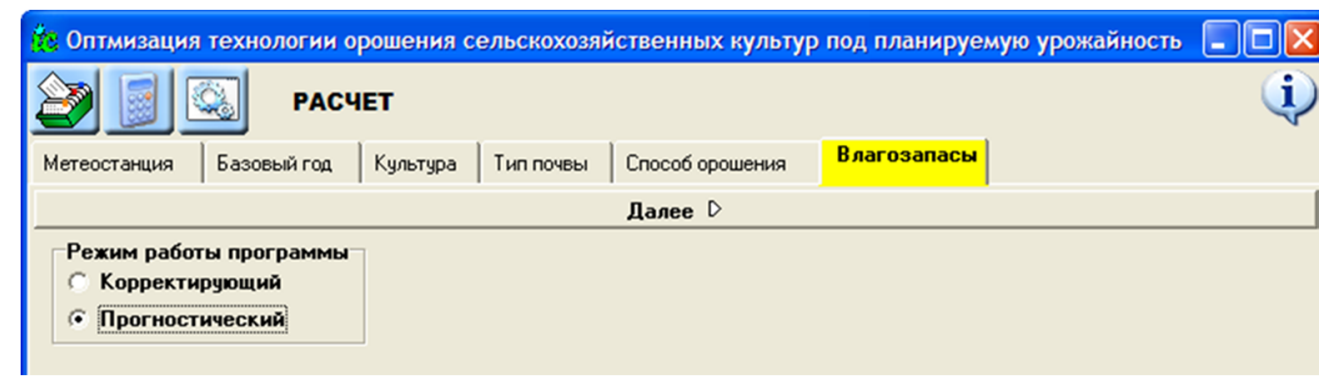

Рисунок 7 - Выбор режима работы

Figure 7 - Selecting the operating mode

Для реализации прогнозного режима расчета поливных норм для планируемой урожайности орошаемых культур требуется предварительный ввод исходных данных.

Технология использования системы включает следующие 6 этапов, реализующие ввод соответствующих им данных. нок 8).

На этапе 1 вводятся наименование федерального округа и метеостанции (рису-

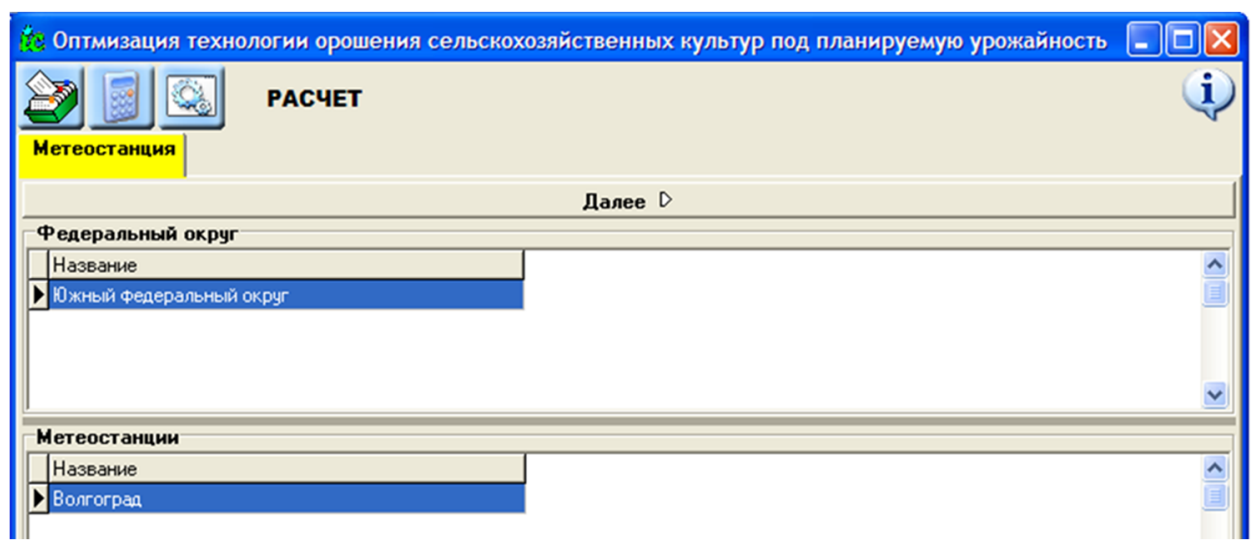

Рисунок 8 - Этап 1: ввод данных «Метеостанция»

Figure 8 - Step 1: data entry «Weather Station» 
На этапе 2 вводятся ежегодные данные биоклиматических показателей (рисунок 9), разбитых по месяцам и учитываемым декадам.

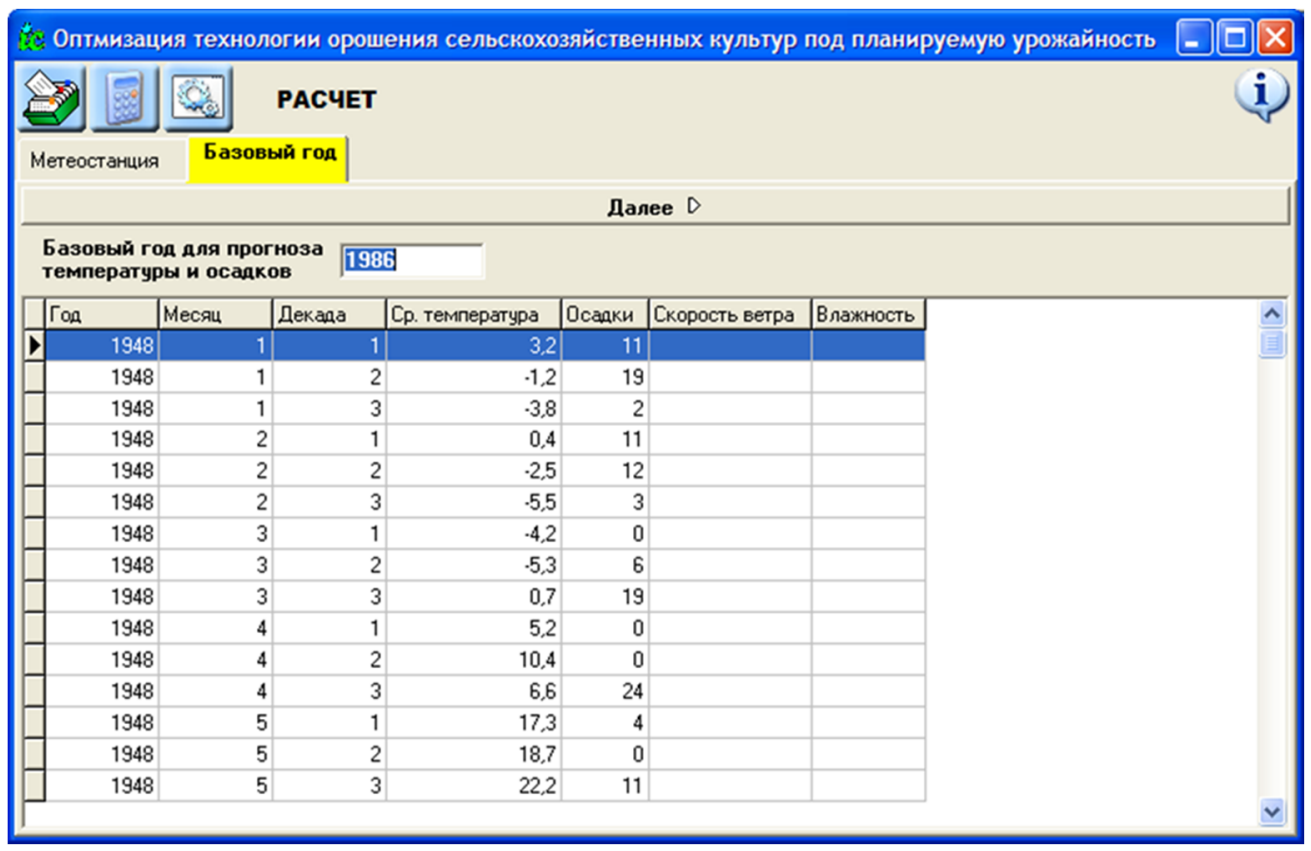

Рисунок 9 - Этап 2: ввод данных «Базовый год»

Figure 9 - Step 2: entering the «Base year data»

На этапе 3 на вкладке «Культура» вводят данные о сельскохозяйственной культуре: наименование, сорт, а также вид сельскохозяйственной продукции (рис. 10).

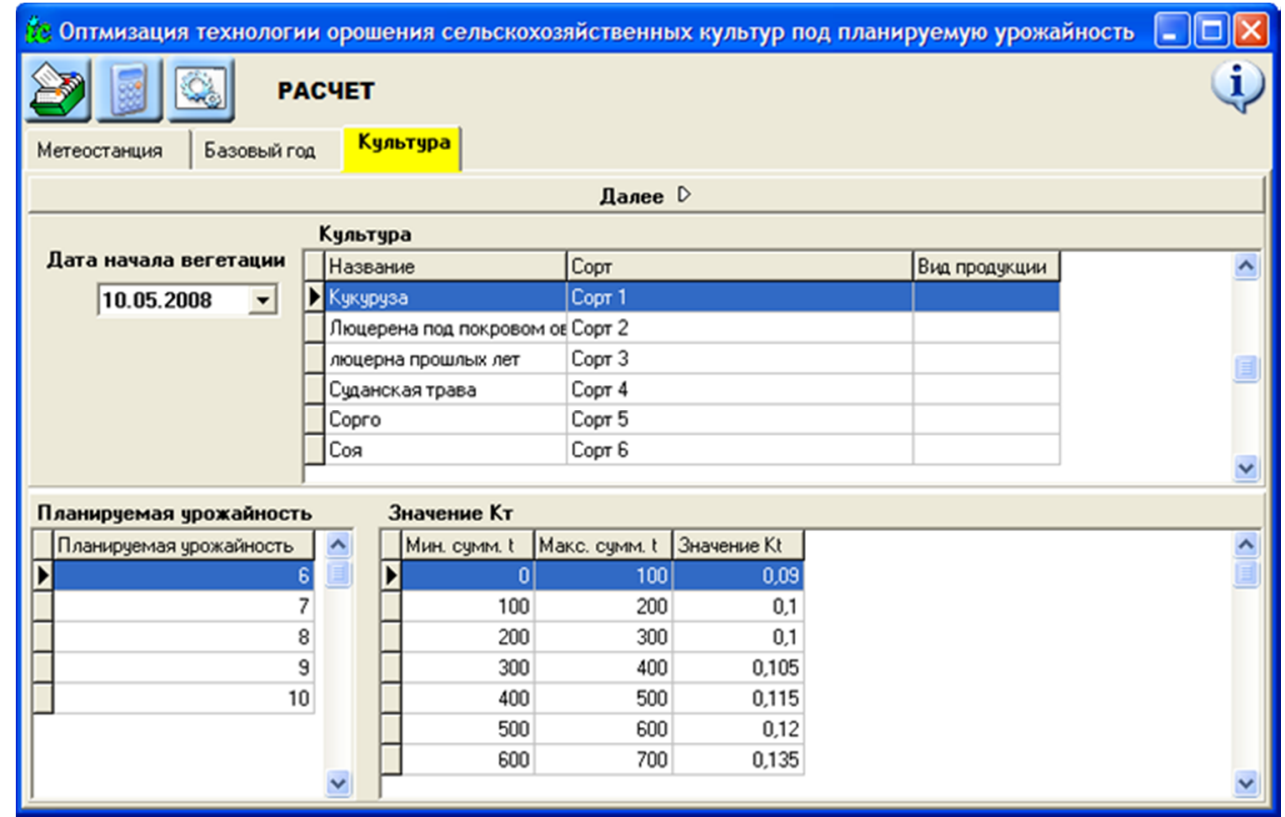

Рисунок 10 - Этап 3: ввод данных «Орошаемая сельскохозяйственная культура»

Figure 10 - Step 3: data entry «Irrigated agricultural crop»

На этапе 4 водится тип и подтип почвы, а также их агрофизические свойства. Предусмотрена возможность задания большинства базовых параметров, учитываемы в последующих расчетах (рисунок 11). 


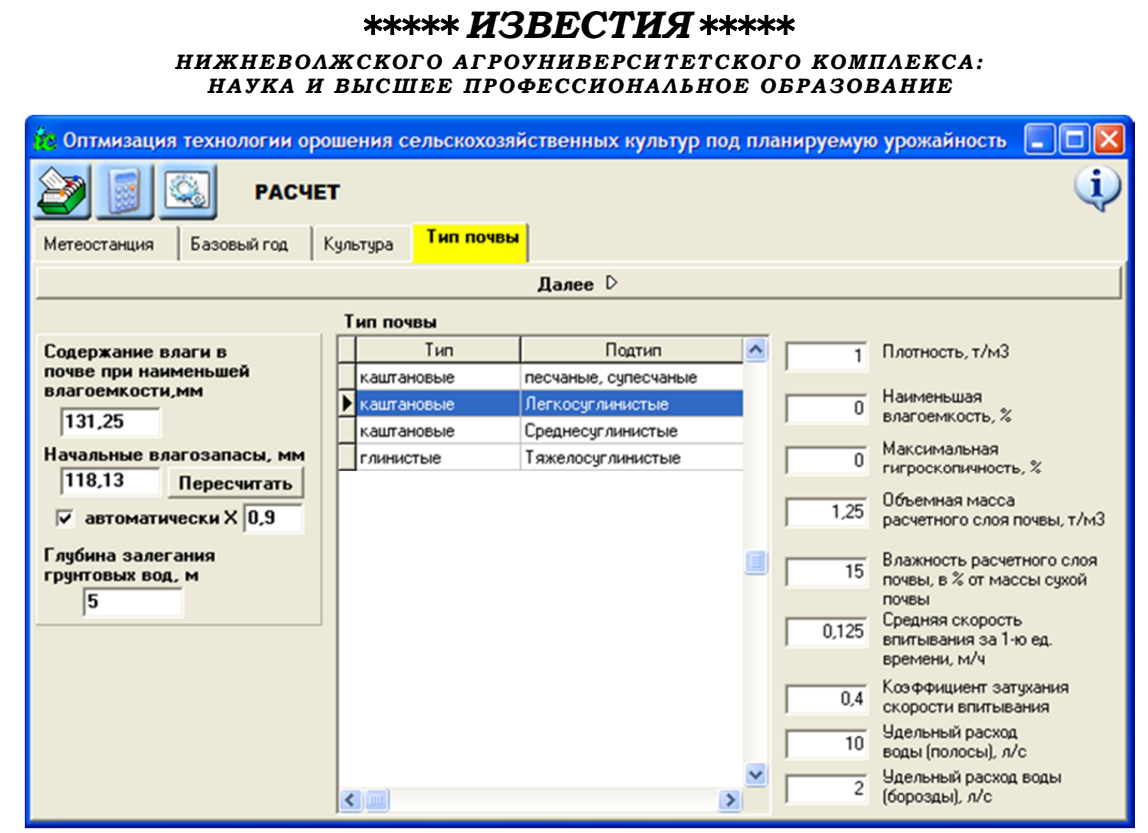

Рисунок 11 - Этап ввода данных «Тип и агрофизические характеристики почв»

Figure 11 - Data entry stage «Soil type and agrophysical characteristics»

На вкладке «Способ орошения» (рисунок 12) выбирают из справочника «способ орошения», в зависимости от него вводят характеристики.

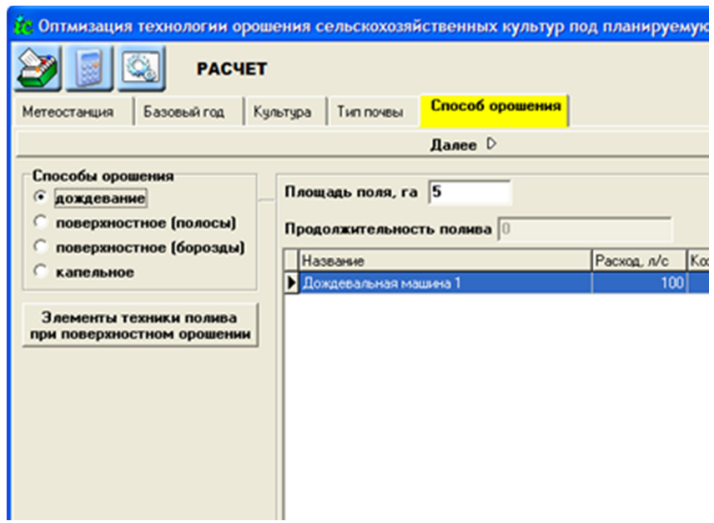

a)

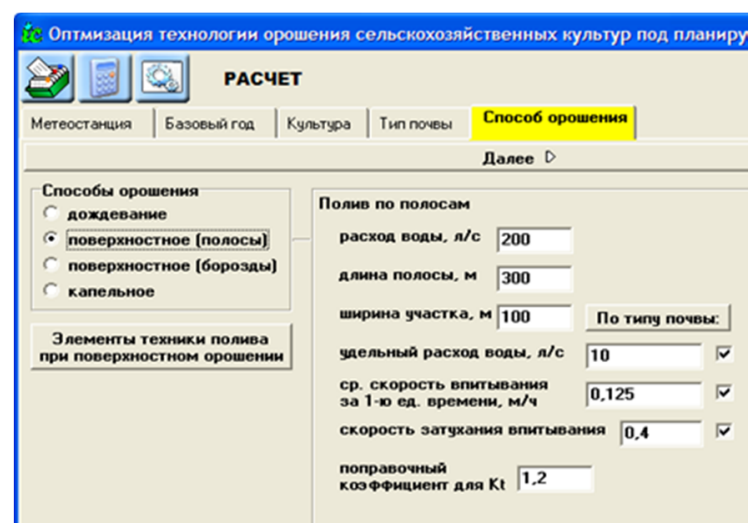

б)

Рисунок 12 - Этап ввода данных: «Способ орошения» а) Дождевание; б) Способ орошения - поверхностный, по полосам)

Figure 12 - Data entry stage: «Irrigation method»

a) Sprinkling; b) Irrigation method - surface, by stripes)

В частности, при орошении дождеванием (рисунок 11a) указывают следующие данные: площадь орошаемого поля, время полива, наименование дождевальной машины, расход воды при поливе, а также коэффициент использования рабочего времени. При поливе по полосам указывается расход воды в л/с, длина полосы, ширина участка, в зависимости от типа почвы, удельный расход воды, средняя скорость впитывания за первую единицу времени, скорость затухания впитывания и поправочный коэффициент для $K t$.

Программой также реализована наглядная визуализация результатов выполняемых расчетов, в частности динамики содержания влаги в почве, которая при необходимости может выводиться в файл и на печать. Состав выводимых программой показателей можно гибко настраивать по требованиям пользователя. Результаты расчетов можно выводить в табличной форме или графическом виде (рисунок 13). 
Приведенная на рисунке 13 диаграмма наглядно демонстрирует прогнозируемое изменение влажности почвы в соответствии с осадками и предполивными порогами в процессе реализации заданного режима орошения по фазам вегетационного цикла.

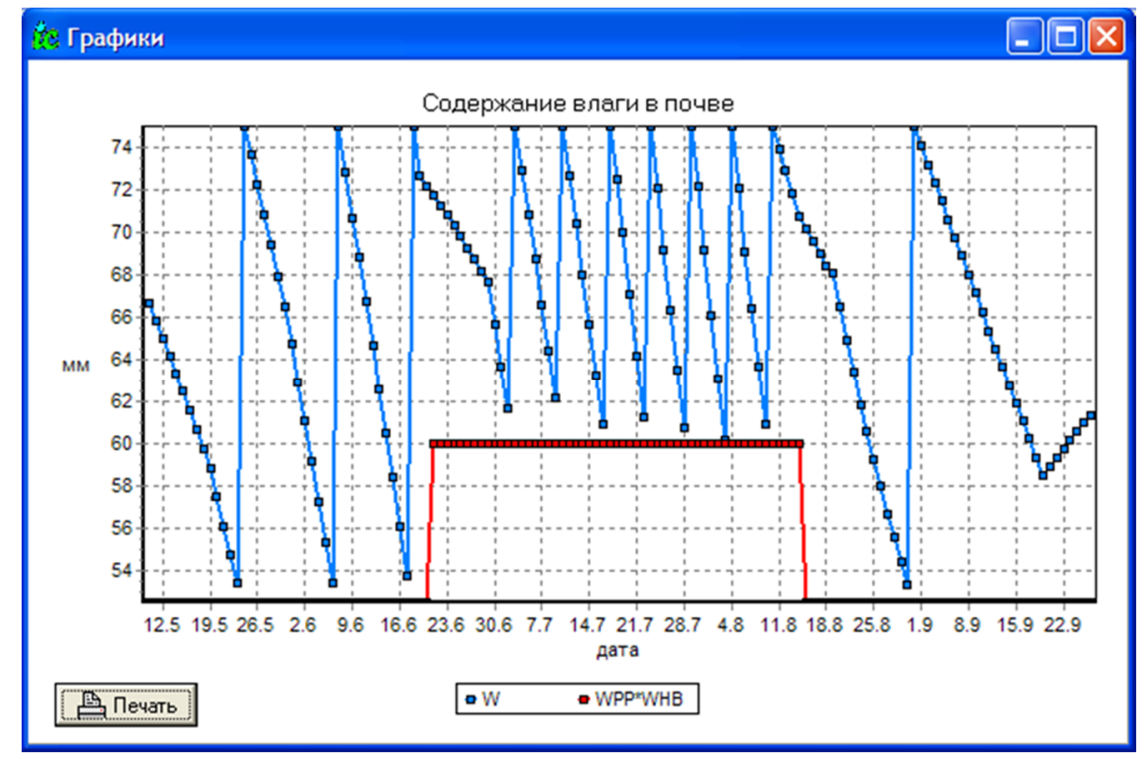

Рисунок 13 - Диаграмма предполивных порогов влажности и динамики почвенной влажности

Figure 13 - Diagram of pre-flood humidity thresholds and soil moisture dynamics

Тестирование разработанной программы осуществлялось совместно с ГНУ ВНИИОЗ по данным, полученным на опытных полях хозяйства «Орошаемое» Волгоградской области.

\section{Выводы.}

1. Применение информационно-советующих систем (ИСС) в орошаемом земледелии позволяет повысить научную обоснованность при реализации задаваемых режимов орошения сельскохозяйственных культур.

2. Разработанная программная система, функционирующая в двух режимах прогнозном и корректирующем, - обеспечивает повышение устойчивости возделывания сельскохозяйственных культур, достигаемое за счет повышения обоснованности управления оросительными процессами на основе прогнозирования сроков и числа поливов, рассчитываемых под заданную урожайность.

3. Применение ИСС, реализуемых посредством разработанной компьютерной программы, для выращивания орошаемых сельскохозяйственных культур обеспечивает экономию оросительной воды и повышение обоснованности управленческих решений в области выращивания орошаемых сельскохозяйственных культур за счет обеспечения возможности более точного выдерживания запроектированных параметров режима орошения.

\section{Библиографический список}

1. Аксенов А. Г. Анализ интеллектуальных систем поддержки принятия решений в сельском хозяйстве // Электротехнологии и электрооборудование в АПК. 2019. № 3 (36). С. 46-51.

2. Алтыбаев А. Н. К формированию онтологии информационной системы для поддержки принятия инженерно-технологических решений в агробизнесе // Инновации в сельском хозяйстве. 2016. № 1 (16). С. 298-303.

3. Векленко В. И., Петренко Н. Н., Пашков В. Ю. Проектирование базы данных системы моделей оптимального планирования сельскохозяйственного производства // Вестник Курской государственной сельскохозяйственной академии. 2013. № 1. С. 33-36. 
4. Васильев С. М., Митяева Л. А. Оценка процессов деградации орошаемых земель в рамках калибровки сервисов мониторинга сельскохозяйственных земель // Научный журнал Российского НИИ проблем мелиорации. 2016. № 4 (24). С. 70-85. https://elibrary.ru/download/elibrary 27320488 67297494.pdf

5. Гагарин А. Г., Рогачев А. Ф. Применение искусственных нейронных сетей для прогнозирования урожайности на основе анализа кросс-региональных данных // Известия Нижневолжского агроуниверситетского комплекса: наука и высшее профессиональное образование. 2018. № 2. С. 339-346.

6. Герасимов А. Н., Башкатова Т. А. Информационно-аналитический инструментарий обоснования управленческих решений в экономике традиционно аграрного региона // Вестник АПК Ставрополья. 2016. № 20/1 (4). С. 8-12.

7. Глазунов Г. П., Афонченко Н. В., Санжаров А. И. Структура базы данных природноресурсного потенциала агроландшафтов // Вестник Курской государственной сельскохозяйственной академии. 2017. № 8. С. 6-11.

8. Ильиных А. Л. Разработка базы данных автоматизированной информационной системы мониторинга земель сельскохозяйственного назначения // Гео-Сибирь. 2011. Т. 3. № 2. С. 124-129.

9. Мелихова Е. В. Моделирование и обоснование ресурсосберегающих параметров капельного орошения при возделывании корнеплодов: монография. Волгоград: ФГБОУ ВО Волгоградский ГАУ, 2017. $112 \mathrm{c.}$

10. Мелихова Е. В., Бородычев В. В., Рогачев А. Ф. Функционально-морфологический анализ и совершенствование технических средств комбинированного орошения // Мелиорация и водное хозяйство. 2018. № 4. С. 30-36.

11. Николаенко А. Н., Кавокин А. А. Концепция разработки информационноаналитической системы "Мелиорация" // Природообустройство. 2019. № 3. С. 6-13.

12. Оптимальное управление поливами на основе современных вычислительных алгоритмов / В. В. Бородычев, М. Н. Лытов, А. С. Овчинников, В. С. Бочарников // Известия Нижневолжского агроуниверситетского комплекса: наука и высшее профессиональное образование. 2015. № 4 (40). С. 21-28.

13. Подлипнов В. В., Щедрин В. Н., Бабичев А. Н. Экспериментальное определение влажности почвы по гиперспектральным изображениям // Компьютерная оптика. 2018. Т. 42. № 5. C. $877-884$.

14. Рогачев А. Ф. Системный анализ и прогнозирование временных рядов урожайности на основе автокорреляционных функций и нейросетевых технологий // Известия Нижневолжского агроуниверситетского комплекса: наука и высшее профессиональное образование. 2018. № 3 (51). C. 309-316.

15. Control over grape yield in the north-eastern region of ukraine using mathematical modeling / B. Shulika, A. Porvan, O. Vysotska, A. Nekos, A. Zhemerov // Eastern-European Journal of Enterprise Technologies. 2017. № 2/3 (86). Pp. 51-59.

16. Rogachev A. F., Melikhova E. V., Shokhnekh A. V. Monitoring and economic \& mathematical modeling of manufacture and consumption of agricultural products as a tool of food security management // Espacios. 2018. V. 39. № 1. P. 1.

17. Russello H. Convolutional neural networks for crop yield prediction using satellite images // IBM Center for Advanced Studies. 2018. https:/esc.fnwi.uva.n1/thesis/centraal/files/f1570224447.pdf.

18. Trukhachev V. I. Estimation of condition of cultivated pastures under remote sensing of earth // Engineering for Rural Development Proceedings. 2019. P. 442-449.

\section{Conclusions.}

1. The use of information and advisory systems (ISS) in irrigated agriculture allows to increase the scientific validity of the implementation of the specified irrigation regimes of agricultural crops.

2. The developed software system, which operates in two modes - predictive and corrective-provides an increase in the stability of crop cultivation, achieved by increasing the validity of irrigation process management based on the prediction of the timing and number of watering calculated for a given yield. 
3. The use of ISS implemented through the developed computer program for the cultivation of irrigated crops provides irrigation water savings and increases the validity of management decisions in the field of growing irrigated crops by providing the possibility of more accurate maintenance of the projected parameters of the irrigation regime.

\section{References}

1. Aksenov A. G. Analiz intellektual'nyh sistem podderzhki prinyatiya reshenij v sel'skom hozyajstve // Jelektrotehnologii i jelektrooborudovanie v APK. 2019. № 3 (36). P. 46-51.

2. Altybaev A. N. K formirovaniyu ontologii informacionnoj sistemy dlya podderzhki prinyatiya inzhenerno-tehnologicheskih reshenij v agrobiznese // Innovacii v sel'skom hozyajstve. 2016. № 1 (16). P. 298-303.

3. Veklenko V. I., Petrenko N. N., Pashkov V. Yu. Proektirovanie bazy dannyh sistemy modelej optimal'nogo planirovaniya sel'skohozyajstvennogo proizvodstva // Vestnik Kurskoj gosudarstvennoj sel'skohozyajstvennoj akademii. 2013. № 1. P. 33-36.

4. Vasil'ev S. M., Mityaeva L. A. Ocenka processov degradacii oroshaemyh zemel' v ramkah kalibrovki servisov monitoringa sel'skohozyajstvennyh zemel' // Nauchnyj zhurnal Rossijskogo NII $\begin{array}{lllllll}\text { problem melioracii. } & 2016 . & \text { № } & 4 & \text { (24). } & \text { P. } & \text { 70-85. }\end{array}$ https://elibrary.ru/download/elibrary_27320488_67297494.pdf

5. Gagarin A. G., Rogachev A. F. Primenenie iskusstvennyh nejronnyh setej dlya prognozirovaniya urozhajnosti na osnove analiza kross-regional'nyh dannyh // Izvestiya Nizhnevolzhskogo agrouniversitetskogo kompleksa: nauka i vysshee professional'noe obrazovanie. 2018. № 2. P. 339-346.

6. Gerasimov A. N., Bashkatova T. A. Informacionno-analiticheskij instrumentarij obosnovaniya upravlencheskih reshenij $\mathrm{v}$ jekonomike tradicionno agrarnogo regiona // Vestnik APK Stavropol'ya. 2016. № 20/1 (4). P. 8-12.

7. Glazunov G. P., Afonchenko N. V., Sanzharov A. I. Struktura bazy dannyh pri-rodnoresursnogo potenciala agrolandshaftov // Vestnik Kurskoj gosudarstvennoj sel'skohozyajstvennoj akademii. 2017. № 8. P. 6-11.

8. Il'inyh A. L. Razrabotka bazy dannyh avtomatizirovannoj informacionnoj sistemy monitoringa zemel' sel'skohozyajstvennogo naznacheniya // Geo-Sibir'. 2011. T. 3. № 2. P. 124-129.

9. Melihova E. V. Modelirovanie i obosnovanie resursosberegayuschih parametrov kapel'nogo orosheniya pri vozdelyvanii korneplodov: monografiya. Volgograd: FGBOU VO Volgogradskij GAU, 2017. $112 \mathrm{p}$.

10. Melihova E. V., Borodychev V. V., Rogachev A. F. Funkcional'no-morfologicheskij analiz i sovershenstvovanie tehnicheskih sredstv kombinirovannogo orosheniya // Melioraciya i vodnoe hozyajstvo. 2018. № 4. P. 30-36.

11. Nikolaenko A. N., Kavokin A. A. Koncepciya razrabotki informacionno-analiticheskoj sistemy "Melioraciya" // Prirodoobustrojstvo. 2019. № 3. P. 6-13.

12. Optimal'noe upravlenie polivami na osnove sovremennyh vychislitel'nyh algoritmov / V. V. Borodychev, M. N. Lytov, A. S. Ovchinnikov, B. C. Bocharnikov // Izvestiya Nizhnevolzhskogo agrouniversitetskogo kompleksa: nauka i vysshee professional'noe obrazovanie. 2015. № 4 (40). P. 21-28.

13. Podlipnov V. V., Schedrin V. N., Babichev A. N. \}ksperimental'noe opredelenie vlazhnosti pochvy po giperspektral'nym izobrazheniyam // Komp'yuternaya optika. 2018. T. 42. № 5. P. 877-884.

14. Rogachev A. F. Sistemnyj analiz i prognozirovanie vremennyh ryadov urozhajnosti na osnove avtokorrelyacionnyh funkcij i nejrosetevyh tehnologij // Izvestiya Nizhnevolzhskogo agrouniversitetskogo kompleksa: nauka i vysshee professional'noe obrazovanie. 2018. № 3 (51). P. 309-316.

15. Control over grape yield in the north-eastern region of ukraine using mathematical modeling / B. Shulika, A. Porvan, O. Vysotska, A. Nekos, A. Zhemerov // Eastern-European Journal of Enterprise Technologies. 2017. № 2/3 (86). Pp. 51-59.

16. Rogachev A. F., Melikhova E. V., Shokhnekh A. V. Monitoring and economic \& mathematical modeling of manufacture and consumption of agricultural products as a tool of food security management // Espacios. 2018. V. 39. № 1. P. 1. 
17. Russello H. Convolutional neural networks for crop yield prediction using satellite images // IBM Center for Advanced Studies. 2018. https://esc.fnwi.uva.nl/thesis/centraal/files/f1570224447.pdf.

18. Trukhachev V. I. Estimation of condition of cultivated pastures under remote sensing of earth // Engineering for Rural Development Proceedings. 2019. P. 442-449.

\title{
Information about the author
}

Alexey F. Rogachev, Professor, Department of Mathematical Modeling and Informatics, Volgograd State Agrarian University (26 Universitetskiy Ave., Volgograd, 400002, Russian Federation), Doctor of Technical Sciences, Professor https://orcid.org/0000-0001-6483-6091, rafr@mail.ru

Elena V. Melikhova, Head of the Department of Mathematical Modeling and Computer Science, Volgograd State Agrarian University (26, Universitetskiy Ave., Volgograd, 400002, Russian Federation), Doctor of Technical Sciences, Associate Professor. https://orcid.org/0000-0001-6483-6091, mel-v07@mail.ru

\section{Информация об авторах}

Рогачев Алексей Фруминович, профессор кафедры "Математическое моделирование и информатика" Волгоградского государственного аграрного университета (РФ, 400002, г. Волгоград, пр-т Университетский, д. 26), доктор технических наук, профессор https://orcid.org/0000-0001-6483-6091, rafr@mail.ru

Мелихова Елена Валентиновна, заведующий кафедры «Математическое моделирование и информатика» Волгоградского государственного аграрного университета (РФ, 400002, г. Волгоград, пр-т Университетский, д.26), доктор технических наук, доцент

https://orcid.org/0000-0001-6483-6091, mel-v07@mail.ru

\section{SELECTION OF THE METHOD OF MOVEMENT OF THE SORGHUM COMBINE WHEN HARVESTING THE BROOM SORGHUM}

\author{
A.I. Ryadnov, O.A. Fedorova, V.A. Baril \\ Volgograd State Agrarian University, Volgograd
}

Received 12.03.2021

Submitted 28.05.2021

\section{Summary}

A comparison is made of four standard non-loop ways of moving a combine harvester when harvesting broom sorghum: with the expansion of the combined mowing from the periphery of the pen to its center, and with the overlap with the expansion of the mowing by the value of the working stroke coefficient. It is established that the values of the coefficient of working strokes for the gon non-loop methods of movement used for harvesting broom sorghum differ by no more than $2 \%$, but at the same time the maximum value of the coefficient of working strokes, and, consequently, the operating productivity, has a sorghum harvester when using the gon non-loop combined method of movement. It is possible to significantly increase the productivity of the sorghum harvester for harvesting broom sorghum by using the gon shuttle method of movement.

\footnotetext{
Abstract

Introduction. Labor productivity in agricultural production largely depends on the potential capabilities of the existing machine and tractor fleet of the economy and is determined by a number of indicators, including the productivity of machine and tractor units, which depends not only on the technical capabilities of the machines that make up the unit, but also on the conditions and the organization of its work. Until now, there are practically no publications related to the study of the influence of the methods of movement of units during agricultural work on their productivity. The purpose of this work is to determine the most efficient way of moving a sorghum harvester in terms of productivity while harvesting broom sorghum. Materials and methods. Based on the analysis of the materials of scientific works, it has been established that it is possible to assess the performance of a sorghum harvester when using possible methods of movement on the paddock when harvesting crops in the same conditions by the coefficient of working strokes. Knowing the coefficient of the working strokes $\varphi$, it is possible to determine the operational performance of the sorghum harvester without linking its determination with many different factors, but to determine it as a function of the technical capabilities of the combine, the kinematics of its movement and the size of the corral to
} 